\title{
Simulated GABA Synaptic Input and L-Type Calcium Channels Form Functional Microdomains in Hypothalamic Gonadotropin-Releasing Hormone Neurons
}

\author{
Peter J. Hemond, ${ }^{1 \star}$ Michael P. 0’Boyle, ${ }^{1 \star}$ Carson B. Roberts, ${ }^{3}$ Alfonso Delgado-Reyes, ${ }^{4}$ Zoe Hemond, ${ }^{1}$ \\ and Kelly J. Suter ${ }^{1,2}$ \\ ${ }^{1}$ Department of Biology and ${ }^{2}$ Neurosciences Institute, University of Texas, San Antonio, San Antonio, Texas 78249, ${ }^{3}$ Bodkin Design and Engineering, LLC, \\ Wellesley Hills, Massachusetts 02481, and ${ }^{4}$ Faculty of Medicine, Autonomous University of Chihuahua, Chihuahua, Chihuahua 31000, Mexico
}

Hypothalamic gonadotropin-releasing hormone $(\mathrm{GnRH})$ neurons integrate the multiple internal and external cues that regulate sexual reproduction. In contrast to other neurons that exhibit extensive dendritic arbors, GnRH neurons usually have a single dendrite with relatively little branching. This largely precludes the integration strategy in which a single dendritic branch serves as a unit of integration. In the present study, we identify a gradient in L-type calcium channels in dendrites of mouse GnRH neurons and its interaction with GABAergic and glutamatergic inputs. Higher levels of L-type calcium channels are in somata/proximal dendrites (i.e., $0-26 \mu \mathrm{m})$ and distal dendrites $(\sim 130 \mu \mathrm{m}$ dendrite length), but intervening midlengths of dendrite $(\sim 27-130 \mu \mathrm{m})$ have reduced L-type calcium channels. Using uncaging of GABA, there is a decreasing GABAergic influence along the dendrite and the impact of $\mathrm{GABA}_{\mathrm{A}}$ receptors is dependent on activation of L-type calcium channels. This results in amplification of proximal GABAergic signals and attenuation of distal dendritic signals. Most interestingly, the intervening dendritic regions create a filter through which only relatively high-amplitude, low-frequency GABAergic signaling to dendrites elicits action potentials. The findings of the present study suggest that GnRH dendrites adopt an integration strategy whereby segments of single nonbranching GnRH dendrites create functional microdomains and thus serve as units of integration.

\section{Introduction}

Gonadotropin-releasing hormone $(\mathrm{GnRH})$ neurons are the final site of integration for multiple internal and external cues regulating sexual reproduction. The GnRH peptide is released episodically from nerve terminals of GnRH axons that project to the median eminence. The pulsatile GnRH signal provides the obligatory stimulus for gonadotropin release from the anterior pituitary and the subsequent support of gonadal function (Herbison, 2006).

The search for mechanisms that control GnRH neuronal activity has focused largely on somata. However, interactions exist between GnRH dendrites, which could coordinate action potentials in $\mathrm{GnRH}$ neurons for pulsatile $\mathrm{GnRH}$ release (Campbell et al., 2009). Moreover, some GnRH dendrites are outside the blood-brain barrier (Herde et al., 2011). Thus, $\mathrm{GnRH}$ dendrites are poised to make critical contributions to the

Received Aug. 11, 2011; revised May 1, 2012; accepted May 4, 2012.

Author contributions: P.J.H., M.P.O., C.B.R., A.D.-R., Z.H., and K.J.S. designed research; P.J.H., M.P.O., and K.J.S performed research; P.J.H., M.P.O., C.B.R., A.D.-R., Z.H., and K.J.S. analyzed data; A.D.-R., Z.H., and K.J.S. wrote the paper.

This work was supported by NIH Grant HD-045436. We thank attendees of the 2011 Gordon Conference: Dendrites: Molecules, Structure and Function for insightful discussions.

*P.J.H. and M.P.O. contributed equally to this work.

Correspondence should be addressed to Kelly J. Suter, One UTSA Circle, BSB 3.03.26, San Antonio, TX 78249. E-mail: kelly.suter@utsa.edu.

DOI:10.1523/JNEUROSCI.4188-11.2012

Copyright $\odot 2012$ the authors $\quad 0270-6474 / 12 / 328756-11 \$ 15.00 / 0$ control of intermittent GnRH release. Finally, recent evidence indicates $\mathrm{GnRH}$ dendrites express tetrodotoxin-sensitive voltage-gated sodium channels, thereby endowing dendrites with the capacity for backpropagation of somatically generated action potentials and dendritic initiation of action potentials (Roberts et al., 2008a).

Several populations of neurons have active conductances in their dendrites with nonuniform distributions (Migliore and Shepherd, 2002). Synaptic input to dendrites can also be nonuniform (Oviedo and Reyes, 2005; Cottrell et al., 2006). Such variations have led to the concept of functional microdomains within dendrites. Most recently, dendrites have been implicated in nonlinear integration of synaptic input in cortical pyramidal neurons. This allows dendritic branches to act as functional units within the nervous system (Branco and Häusser, 2010, 2011).

Multicompartmental modeling experiments first suggested functional microdomains within GnRH dendrites based on voltage-gated sodium channel expression in dendrites. Coupled with the high local axial resistance created by small distal diameters, simulated dendritic action potentials were elicited with relatively modest simulated inputs in distal compartments of GnRH neurons, whereas somatic/proximal dendritic action potentials required higher synaptic stimulation (Roberts et al., 2008a). Moreover, some GnRH neurons exhibited somatic and dendritic action potentials during electrophysiological recordings. Differences in modes of action potential generation (somatic vs den- 
dritic) were attributed to gradients in synaptic phenotypes and densities of innervation along dendrites (Cottrell et al., 2006) and therefore suggested functional microdomains exist within $\mathrm{GnRH}$ dendrites.

In the present study, we experimentally define a functional microdomain in GnRH dendrites created by gradients in GABAergic conductances and L-type calcium channels. Afferents of GABA neurons provide a dominant synaptic drive to $\mathrm{GnRH}$ neurons (Sim et al., 2000) that is depolarizing (DeFazio et al., 2002). Moreover, L-type calcium channels are important in the activity of model GnRH neurons (i.e., GT1-7 cells) (LeBeau et al., 2000; Van Goor et al., 2000) and interact with GABAergic inputs (Spergel et al., 1995; Constantin et al., 2010). Finally, physiological cues that regulate $\mathrm{GnRH}$ release modulate GABAergic inputs (Sullivan et al., 2003; Sullivan and Moenter, 2004). Accordingly, these $\mathrm{GABA}_{\mathrm{A}}$ receptor/L-type calcium channel dendritic microdomains would modulate the efficacy of cues mediated by $\mathrm{GABA}_{\mathrm{A}}$ inputs.

\section{Materials and Methods}

Animals

All studies used adult male mice in which GnRH neurons express green fluorescent protein (GFP) (Spergel et al., 1999). Animals were maintained on a $12 \mathrm{~h}$ light/dark cycle with ad libitum access to standard rodent chow and water. All procedures performed on animals were reviewed and approved by the Institutional Animal Care and Use Committee at University of Texas, San Antonio, and were in accordance with the NIH Guide for Care and Use of Laboratory Animals.

\section{Electrophysiology}

Tissue preparation. Hypothalamic slices $(300 \mu \mathrm{m})$ were prepared in the sagittal plane using a vibrating microtome (HM 650V; Sigmann Elektronik). Following decapitation under isoflurane anesthesia, brains were removed and placed in cold $\left(1-2^{\circ} \mathrm{C}\right)$ artificial CSF (ACSF) solution containing the following (in $\mathrm{mM}$ ): $125 \mathrm{NaCl}, 24 \mathrm{NaHCO}_{3}, 2.5 \mathrm{KCl}, 1 \mathrm{CaCl}_{2}$, $1 \mathrm{MgCl}_{2}$, and 10 D-glucose, equilibrated with $95 \% \mathrm{O}_{2} / 5 \% \mathrm{CO}_{2}, \mathrm{pH} 7.3-$ 7.4. Slices were incubated in ACSF for $1-2 \mathrm{~h}$ at $32^{\circ} \mathrm{C}$, transferred to a recording chamber mounted on the stage of an upright microscope (Axioskop; Carl Zeiss Microimaging), and then continuously perfused with $\operatorname{ACSF}\left(32^{\circ} \mathrm{C}\right)$. GnRH neurons were identified through their GFP expression using epifluorescent excitation at $470 \mathrm{~nm}$ with a $60 \times$ waterimmersion objective.

Pipettes (9-12 M $\Omega$ ) were made from borosilicate glass (A-M Systems) using a pipette puller (PC-10; Narishige) and coated with Sylgard 184 (Dow Corning) to minimize pipette capacitance. Pipettes were filled with the following (in $\mathrm{mm}$ ): $140 \mathrm{~K}$-gluconate, 10 HEPES, 0.2 EGTA, 28.8 $\mathrm{NaCl}, 2 \mathrm{MgCl}_{2}, 4$ adenosine $5^{\prime}$-triphosphate disodium salt hydrate $\left(\mathrm{C}_{10} \mathrm{H}_{14} \mathrm{~N}_{5} \mathrm{Na}_{2} \mathrm{O}_{13} \mathrm{P}_{3} \cdot \mathrm{H}_{2} \mathrm{O}\right), 0.4$ guanosine 5 '-triphosphate sodium salt hydrate $\left(\mathrm{C}_{10} \mathrm{H}_{16} \mathrm{~N}_{5} \mathrm{O}_{14} \mathrm{P}_{3} \cdot \mathrm{Na}^{+}\right), 0.05$ spermine, and 5 glutathione with $0.5 \%$ biocytin. This renders the reversal potential for chloride the principal current carrier for the $\mathrm{GABA}_{\mathrm{A}}$ receptor $\left(E_{\mathrm{GABA}_{\mathrm{A}}}\right)=-36.5 \mathrm{mV}$, in GnRH neurons (DeFazio et al., 2002).

Dynamic current clamping. Dynamic current clamping is used to apply the electrical equivalents of synaptic currents to somata of neurons. During a recording, the instantaneous values of the membrane potential, $V_{\mathrm{m}}$ (from the neuron), the conductance $\left(g_{\mathrm{i}}\right)$ from the conductance waveform, and the reversal potential $\left(E_{\mathrm{i}}\right)$ are used to calculate the current to be injected $\left(I_{\mathrm{i}}\right)$ using Ohm's law $\left[I_{\mathrm{i}}=g_{\mathrm{i}}\left(V_{\mathrm{m}}-E_{\mathrm{i}}\right)\right]$. Thus, injected current mimics biophysical currents. The currents that flow in living cells, such as the $\mathrm{GABA}_{\mathrm{A}}$ synaptic current, are characterized by a time-varying conductance and a reversal potential. Therefore, one can construct simulated synapses with defined magnitudes and time courses of conductance and the reversal potential. Before experiments, predefined patterns of synaptic input were simulated in GENESIS. A conductance waveform was generated that is the sum of many individual postsynaptic conductance events. This waveform can then be applied multiple times to the same cell, or to different cells.
During recordings, membrane potential changes in living neurons. Dynamic current clamping uses feedback from a neuron to a computer, where $V_{\mathrm{m}}$ is updated online (in our experimental configuration at 10 $\mathrm{kHz}$ ). The injected current is adjusted based on this feedback loop to reflect changes in driving force that occur with alterations in $V_{\mathrm{m}}$ (Sharp et al., 1993). Thus, the magnitude of inputs applied using the dynamic current clamp depends on the activity of the recorded neuron.

To accurately simulate excitatory GABAergic input with the reported $E_{\mathrm{GABA}_{\mathrm{A}}}=-36.5 \mathrm{mV}$ (DeFazio et al., 2002), the time courses of the conductance of the simulated synapses used for our dynamic currentclamping experiments were defined using a double-exponential function as follows:

$$
g_{\text {syn }}(t)=\frac{\bar{g}_{\text {syn }}}{\tau_{1}-\tau_{2}}\left(e^{-\left(\frac{t}{\tau_{1}}\right)}-e^{-\left(\frac{t}{\tau_{2}}\right)}\right) .
$$

In Equation 1, the variables $\tau_{1}$ and $\tau_{2}$ are the rise and fall time constants, $t$ is the time, and $\bar{g}_{\text {syn }}$ is the conductance amplitude.

Simulated patterns of input, with semirandom Gaussian distributions of activation times at various mean frequencies, were computed using the General Neural Simulation System (GENESIS; http://www.genesis-sim. org/GENESIS/). $\mathrm{GABA}_{\mathrm{A}}$-type synapses were constructed using Equation 1 with a $\tau_{1}$ and $\tau_{2}$ of 1.0 and $10 \mathrm{~ms}$, respectively. We used peak synaptic conductance levels for GABA inputs of 250, 500, and $1250 \mathrm{pS}$ in separate simulations to study the impact of a range of plausible sizes of synaptic inputs. For dynamic-clamping experiments to determine the specificity of $\mathrm{GABA}_{\mathrm{A}}$ and L-type calcium channel interactions, AMPA-type excitatory inputs were applied to $\mathrm{GnRH}$ somata. Simulated AMPA-type inputs were constructed using Equation 1 with a $\tau_{1}$ and $\tau_{2}$ of 0.5 and $1.2 \mathrm{~ms}$, respectively, and conductances of $500 \mathrm{pS}$. We have previously verified these conductance levels in GnRH neurons relative to endogenous postsynaptic currents (PSCs) mediated by $\mathrm{GABA}_{\mathrm{A}}$ receptors when $E_{\mathrm{GABA}_{\mathrm{A}}}=$ $-36.5 \mathrm{mV}$ (DeFazio et al., 2002; Roberts et al., 2008b) and AMPA receptors (Suter, 2004).

When studying activity of GnRH neurons in response to simulated

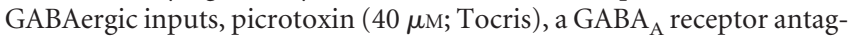
onist, was added to the bath solution to block endogenous $\mathrm{GABA}_{\mathrm{A}}$ receptor activation. We also used 6-cyano-7-nitroquinoxaline-2,3-dione (CNQX) $(20 \mu \mathrm{M})$ to block AMPA receptors to isolate GABA. During dynamic-clamping experiments with simulated AMPA inputs, CNQX $(20 \mu \mathrm{M})$ was used to block endogenous AMPA receptors. The average age of mice used for GABA and AMPA dynamic-clamp recordings was $67.5 \pm 6.1 \mathrm{~d}(n=27)$ and $53.2 \pm 3.8 \mathrm{~d}(n=5)$, respectively.

Analysis: spike-triggered averaging. The analysis of dynamic-clamping data involves the technique of spike-triggered averaging to examine how $\mathrm{GnRH}$ neurons integrate synaptic inputs. To understand the nature of inputs that lead to spikes, one identifies the time course of simulated inputs in a short temporal window before and after each spike (for analysis details, see Roberts et al., 2008b). Spike-triggered averaging on dynamic-clamping data was performed with custom software.

Cell-attached recordings. We have previously validated our cellattached recording approach for the detection of action potentials with low-resistance seals ( $\sim 30-50 \mathrm{M} \Omega$ ) (Hemond and Suter, 2010). We used Axoclamp 2B (Molecular Devices) in current-clamp mode as the primary amplifier in series with a second amplifier (A-M Systems 3000) to increase signal detection and to allow for detection of action potentials. Glutamatergic excitation mediated by AMPA receptors was blocked with CNQX $(20 \mu \mathrm{M})$ to isolate GABAergic inputs. Neurons were visually mapped to schematics and placed in $4 \%$ paraformaldehyde after recordings. Slices were then subjected to immunocytochemistry for L-type calcium channels (see below). The average age of mice used for cell-attached recordings was $80 \pm 0.31 \mathrm{~d}(n=6)$.

Spikes times were obtained by calculating the time-to-peak above $\geq 4$ times root mean square of the signal. The interspike intervals were pooled from six cells (each with 25-s-long spike trace), and the commonly used parameter for measuring variation, the coefficient of variation, was calculated.

Uncaging of GABA. Whole-cell recordings were performed as previously detailed (see above) (Roberts et al., 2008b). Using the $60 \times$ objec- 
tive and microscope described in the section above, the Dual Port Wide condensor (TILL Photonics) with all apertures adjusted to be maximally open was attached in the place of the X-cite series 120 epifluorescence condensor, which is standard with Zeiss microscopes. The original X-cite series 120 fiber optic cable was reattached to the "direct arm" of this condensor, allowing unimpeded epifluorescence light source to pass into the microscope, and was used for locating the GnRH neurons. The fiber optic cable of a TILL Photonics Rapp OptoElectronic JML-C2 xenon flashlamp system was attached to the side port of this condensor, which contained the supplied UV dichroic mirror positioned to reflect UV photoflash emissions from the JML-C2 into the microscope. A 400dclp D350/50 $\times$ DAPI filter set (Chroma Technology) with a metal slug in the emission port was inserted into the filter block turret of the Zeiss microscope and selected during all UV uncaging flash events.

Using the "C2" capacitive setting and a voltage of $200 \mathrm{~V}$ on the JML-C2, the user generated flash emissions. An SP395 UV optical filter was placed in the lamp cowel on the front of the unit to attenuate longer wavelengths and allow UV to pass. DPNI-caged GABA [1-(4-aminobutanoyl)-4-[1,3bis(dihydroxyphosphoryloxy)propan-2-yloxy]-7-nitroindoline] (Tocris Bioscience) was prepared in a $2 \mathrm{~mm}$ concentration in a small volume of ACSF and infused into the tissue well using a recirculation system isolated from the main ACSF system. The average age of mice used for recordings during uncaging of GABA was $68.5 \pm 4.6 \mathrm{~d}(n=14)$.

Cell filling with biocytin. In experiments in which GABA was uncaged along the dendrite, GnRH neurons were filled with biocytin from the pipette solution after achieving the whole-cell recording configuration. Slices containing biocytin-filled GnRH neurons were placed in $4 \%$ paraformaldehyde immediately after filling. Seventy-two hours later, biocytin-containing neurons were relocated with NeutrAvidin, Cascade Blue conjugate (1:100; Invitrogen). Relocated GnRH neurons containing biocytin were viewed using DAPI optics to visualize the Cascade Blue signal, as well as in the FITC channel to verify that the endogenous GFP fluorescence emission had survived the procedure. Positive slices were subjected to immunocytochemistry for L-type calcium channels (see below).

\section{Anatomical experiments: L-type calcium channel immunohistochemistry}

Animals were deeply anesthetized with an intraperitoneal injection of sodium pentobarbital (Butler Schein) and immediately transcardially perfused with cold lactated Ringer's followed by cold paraformaldehyde (Ted Pella). A concentration of $4 \%$ paraformaldehyde in $0.1 \mathrm{~m}$ phosphate buffer was used. The brain was then removed and immersed in the same solution of paraformaldehyde as was used in the perfusion for an additional $24 \mathrm{~h}$ at $4^{\circ} \mathrm{C}$. The brain was then washed in PBS three times at 10 min per wash and stored in PBS at $4^{\circ} \mathrm{C}$.

Brains were sectioned at $50 \mu \mathrm{m}$ in the hemisagittal plane using a Ted Pella Vibratome 1000. All slices were washed three times for $10 \mathrm{~min}$ each with PBS on a shaker at room temperature (RT). Slices were then blocked with $250 \mu \mathrm{l}$ of $5 \% \mathrm{BSA}, 0.2 \%$ Triton X-100, and $6 \%$ normal goat serum in PBS for $1 \mathrm{~h}$ on a shaker at RT or alternatively overnight at $4^{\circ} \mathrm{C}$. The primary L-type antibody ( anti-Ca $_{\mathrm{v}} 1.2$; Alomone Labs) was added at a concentration of 1:250 along with the fresh block as described above. We focused on $\mathrm{Ca}_{\mathrm{v}} 1.2$ channels based on preliminary immunocytochemistry experiments and activation voltages for L-type calcium channel subtypes (Lipscombe et al., 2004).

Slices were incubated for $3-4 \mathrm{~d}$ at $4^{\circ} \mathrm{C}$. Following incubation, all slices were washed three times for $10 \mathrm{~min}$ each with PBS on a shaker at RT. The rhodamine goat-hosted anti-rabbit secondary antibody (A11036; Invitrogen) was applied at a concentration of 1:100 in 250 $\mu \mathrm{l}$ of PBS and incubated for $2 \mathrm{~h}$ at RT on a light protected shaker. Tissues were then washed three times for 10 min each with PBS on the shaker at RT and then visualized on a Nikon Eclipse 600 equipped with epifluorescence to verify the presence of the secondary rhodamine fluorescence to the L-type calcium primary antibody, as well as the postprocedural survival of the endogenous GFP emission from the GnRH neurons themselves. We examined the distribution of calcium channels labeled with the rhodamine secondary only in GnRH neurons that had dendrites with lengths of at least $150 \mu \mathrm{m}$ ( 34 of $42 \mathrm{GnRH}$ neurons derived from 24 animals).

\section{Confocal image acquisition}

Excitation and 3-D stack imaging of all fluorophores was performed using a sequential scan. Each channel was sampled with Nyquist resolution and one Airy unit set individually for each fluorophore and used a $z$-step of $0.45 \mu \mathrm{m}$ on the focus motor for each scan using an Olympus Plan-Neofluor DIC $40 \times$ oil-immersion objective. Images were analyzed using a Zeiss LSM 510 Meta laser-scanning confocal microscope and associated acquisition software (release 4.2; SP1, Heidelberg Germany). The GFP was excited with the $488 \mathrm{~nm}$ line from the argon gas laser of the system (emission filter of 505-570 nm). To excite the rhodamine secondary for the L-type calcium channels, we used a helium-neon laser $543 \mathrm{~nm}$ line (emission LP 560 filter).

\section{Image analysis}

Images were subjected to 3-D deconvolution using AutoQuant (version 1.4.1; Media Cybernetics). Using a process called blind point spread function (blind PSF) deconvolution, the mathematical inverse of the convolving function that describes the theoretical pathway and distortions the light took through the instrument and various media (glass, immersion oil) is computed to more accurately render or (deconvolve) an image. This inverse function is used to reduce the number of falsely assigned photons or photons whose origins were erroneously assigned to portions of the specimen from which they did not arise. This approach also assisted in our colocalization (see below). These deconvolved images were analyzed in Imaris (version X64, 5.1.2; Bitplane).

Colocalization of GFP (pseudocolored green) and the L-type calcium channels (pseudocolored red) was determined using the Imaris colocalization function. Colocalization (pseudocolored white) is tagged if signals from the two channels occurred within the same voxel, defined by our optics as a $0.41(x$-axis $) \times 0.41(y$-axis $) \times 0.45(z$-axis $) \mu \mathrm{m}$ cube. These images were colocalized in full $3-\mathrm{D}$ without projecting or collapsing the image stacks.

\section{Results}

There is now general agreement that $\mathrm{GABA}_{\mathrm{A}}$ receptor activation is excitatory in $\mathrm{GnRH}$ neurons with a defined $E_{\mathrm{GABA}_{\mathrm{A}}}=-36.5 \mathrm{mV}$ (DeFazio et al., 2002). During endogenous activity, several possible explanations could account for the earlier differences between GnRH neurons in their response to GABAergic excitation. These include a shift in $E_{\mathrm{GABA}_{\mathrm{A}}}$ due to changes in intracellular chloride concentrations during times of high GABA input (Gulledge and Stuart, 2003), high levels of NMDA receptor activation (Lee et al., 2011), or differences in chloride transporter expression between GnRH neurons (Leupen et al., 2003).

In our dynamic-clamping experiments, we fixed the value of $E_{\mathrm{GABA}_{\mathrm{A}}}$ used in our simulated GABAergic conductances, making it independent of chloride concentrations. Nonetheless, one of the limitations of dynamic current-clamping is that the current injecting electrode is located at the soma. This is an accurate way of simulating somatic synaptic inputs/proximal dendritic inputs but may not adequately reflect interactions when inputs are distributed along the dendrite. We also used ratios of intracellular and extracellular chloride concentrations to control chloride gradients. However, activity of chloride transporters may still be effective at altering local chloride concentrations particularly in the smaller compartments of distal dendrites. These limitations underscore the complexity of studying chloride-related processes in many, if not most, populations of neurons. In the present study, differences were considered significant at $p \leq 0.05$.

Firing rates in $\mathrm{GnRH}$ neurons during application of identical input profiles of simulated synapses with $E_{\mathrm{GABA}_{\mathrm{A}}}=-36.5 \mathrm{mV}$ are shown in Figure $1 A-D$. Action potentials in response to simulated GABAergic excitation were detected in some GnRH neurons, but firing was completely absent in other GnRH neurons using the same stimulus conditions. We termed GnRH neurons that exhibited action potentials in response to GABAergic excitation as responder 
Representative responder $\mathrm{EGABA}=-36.5 \mathrm{mV}$.

A

Unitary Conductance: $500 \mathrm{pS}$

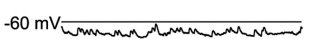

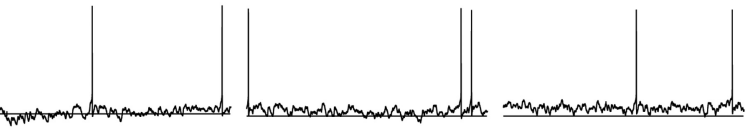
B Unitary Conductance: $1250 \mathrm{ps} \mid$

Representative Non-responder

EGABA $=-36.5 \mathrm{mV}$

C Unitary Conductance: $500 \mathrm{pS}$

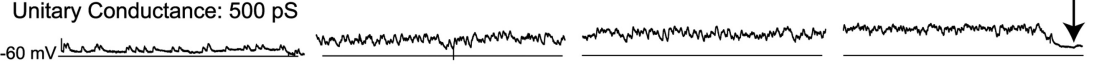

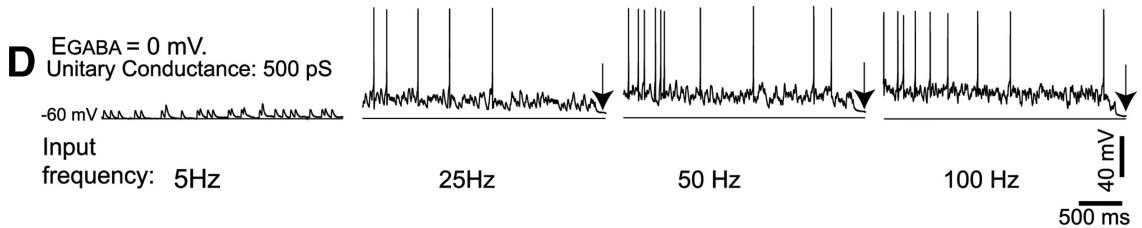

E Firing rates of all GnRH neurons

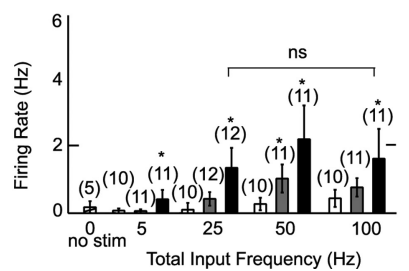

F Firing rates of responders

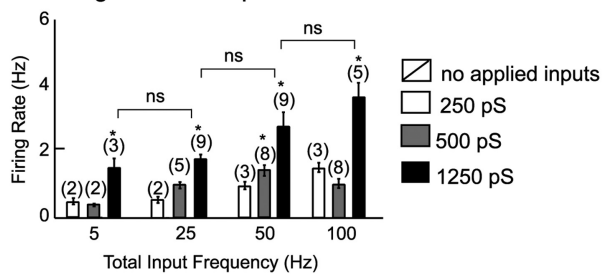

Figure 1. Dynamic clamping distinguishes GnRH neurons that respond to simulated GABAergic excitation with action potentials ("responder") from GnRH neurons that do not generate GABA-driven action potentials (nonresponder). Representative activity of a responder GnRH neuron to simulated GABAergic excitation using synapses with unitary conductances of $500 \mathrm{pS}(\boldsymbol{A})$ and $1250 \mathrm{pS}(\boldsymbol{B})$. Representative firing of a nonresponder GnRH neuron to GABAergic excitation with synapses using unitary conductances of $500 \mathrm{pS}$ and reversal potentials of simulated inputs of either $-36.5 \mathrm{mV}(\boldsymbol{C})$ or $0 \mathrm{mV}(\boldsymbol{D})$. Cand $\boldsymbol{D}$ show the response of the same GnRH neuron to the same GABAergic input profiles in which only the reversal potential of the simulated inputs was changed during recording. The arrows in $\boldsymbol{C}$ and $\boldsymbol{D}$ indicate when application of the simulated conductance profile ceased and the membrane potential returned to its resting state some $10-20 \mathrm{mV}$ lower than when simulated GABAergic excitation was applied. Shown are average firing rates of all GnRH neurons $(\boldsymbol{E})$. Shown are average firing rates of only $\mathrm{GnRH}$ neurons that responded to GABAergic excitation with at least one action potential $(\boldsymbol{F})$. Numbers of neurons are indicated in parentheses. The asterisks indicate significance at $p \leq 0.05$ within groups of a given conductance level. Error bars indicate SEM.

GnRH neurons and those that did not respond as nonresponder GnRH neurons. Action potential thresholds ranged from -34 to $-30 \mathrm{mV}$ between cells and did not distinguish responder and nonresponder GnRH neurons.

Responder GnRH neurons fired with application of simulated synapses with unitary conductances of $500 \mathrm{pS}$ (Fig. 1A). This conductance generates currents whose amplitudes closely replicate endogenous GABAergic currents in GnRH neurons when $E_{\mathrm{GABA}_{\mathrm{A}}}=-36.5 \mathrm{mV}$ (Roberts et al., 2008b). Responsive GnRH neurons also exhibited action potentials with the $1250 \mathrm{pS}$ unitary conductance (Fig. $1 \mathrm{~B}$ ). In contrast, nonresponders exhibited no action potentials in response to these same stimuli. Instead, nonresponders had persistently elevated membrane potentials when GABAergic excitation was applied with $E_{\mathrm{GABA}_{\mathrm{A}}}=-36.5 \mathrm{mV}$. The membrane potential was depolarized up to $20 \mathrm{mV}$ above the resting potential but without action potentials (Fig. $1 C$ ). As a positive control, in nonresponder neurons, we applied simulated synapses with $E_{\mathrm{GABA}_{\mathrm{A}}}=0 \mathrm{mV}$ by altering $E_{\mathrm{GABA}_{\mathrm{A}}}$ in our dynamic clamping equation online, after testing the response of the neuron to inputs in which $E_{\mathrm{GABA}_{\mathrm{A}}}=-36.5 \mathrm{mV}$. Nonresponders exhibited robust firing (Fig. $1 D$ ), indicating these nonresponder cells were capable of generating action potentials.

Firing rates for all tested GnRH neurons and responder $\mathrm{GnRH}$ neurons are summarized in Figure 1, $E$ and $F$, respectively). Highest rates of firing occurred when synapses of unitary conductances of 1250 pS were applied (Fig. 1E,F, black bars). Firing rates ranged from $1.39 \pm$ 0.58 to $2.3 \pm 0.98 \mathrm{~Hz}$ for input frequencies from 25 to $100 \mathrm{~Hz}$. These rates were significantly higher than when no inputs were applied. At the most realistic size of unitary conductance (500 pS), 30\% of $\mathrm{GnRH}$ neurons did not respond to GABAergic excitation even with relatively high frequencies of input (50 and $100 \mathrm{~Hz}$ GABAergic excitation). At the highest levels of GABAergic excitation $(100 \mathrm{~Hz}$ and $1250 \mathrm{pS}$ ), the percentage of nonresponder GnRH neurons increased to $60 \%$, a finding that was suggestive of depolarization block with high levels of GABAergic excitation alone. Alternatively, the reversal potential for chloride appears to be variable in GnRH neurons (Spergel et al., 1999; Sim et al., 2001). Thus, it is possible that spike threshold in these GnRH neurons may be higher than the $-36.5 \mathrm{mV}$ set in the simulated GABA input. Finally, as noted by Moenter and DeFazio (2005), bath application of GABA receptor antagonists would affect all neurons in the slice, making it difficult to separate the impact of GABA on individual GnRH neurons from broader network effects. We attempted to isolate the effect of GABAergic excitation in single GnRH neurons by using dynamic clamping. While not precluding broader network effects and the limitation of dynamic current clamping notwithstanding, our findings suggest a difference in response to GABA excitation at the level of individual GnRH neurons.

The underlying mechanism through which GABA is excitatory in $\mathrm{GnRH}$ neurons may not solely reflect the activation of $\mathrm{GABA}_{\mathrm{A}}$ receptors. Constantin et al. (2010) reported the initial elevation of internal calcium in $\mathrm{GnRH}$ neurons in response to $\mathrm{GABA}_{\mathrm{A}}$ receptor activation was due to L-type voltage-gated calcium channels similar to earlier findings in GT1-7 cells (Spergel et al., 1995).

A marked heterogeneity exists in intrinsic properties of individual hypothalamic GnRH neurons (Sim et al., 2001). One of the heterogeneous properties of adult GnRH neurons appears to be the level of expression and/or activity of calcium channels. Differences in calcium currents have been demonstrated in GnRH neurons in slices from female mice, which were identified by morphology and molecular methods (Sim et al., 2001). More recently, heterogeneity in calcium currents was reported in GnRH neurons in slices from GnRH-GFP males in the mouse line used for the present experiments (Spergel, 2007). Given the observation that activation of $\mathrm{GABA}_{\mathrm{A}}$ receptors activates L-type calcium channels (Spergel et al., 1995; Constantin et al., 2010), 


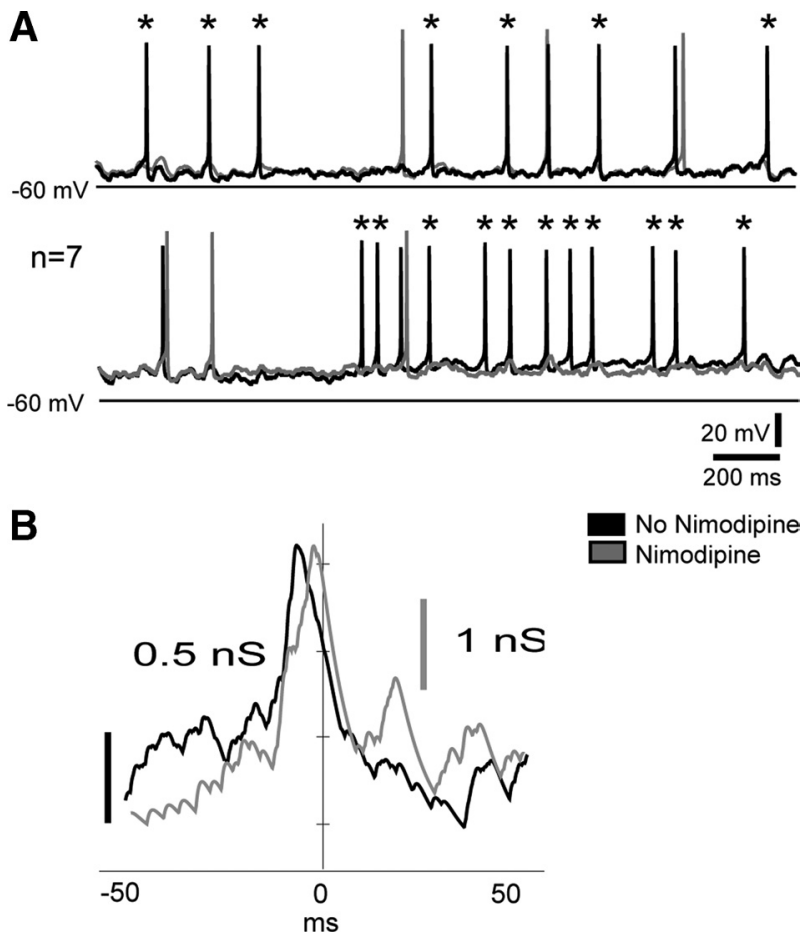

Figure 2. Blocking L-type calcium currents eliminates most action potentials induced by simulated GABAergic excitation in responder GnRH neurons. A, Traces show firing patterns in two different $\mathrm{GnRH}$ neurons before (no block) and after (block) bath application of nimodipine $(10 \mu \mathrm{m})$. The asterisks indicate action potentials that were eliminated following bath application of nimodipine (block). The same profile of simulated GABAergic conductances was used in the control and nimodipine-treated conditions in individual GnRH neurons to allow for a direct comparison within the same neuron. Different profiles of GABAergic excitation (but with the same overall input frequencies) were applied between GnRH neurons to control for any effects of a particular conductance profile. $\boldsymbol{B}$, Spike-triggered averaging on conductance indicates that responder GnRH neurons require higher conductance magnitudes of GABAergic inputs to generate action potentials when L-type calcium channels are pharmacologically blocked.

differences in calcium channel expression could account for the dichotomy in responses to simulated GABAergic excitation. Therefore, we tested the hypothesis that GABAergic excitation evokes firing in responsive GnRH neurons through activation of L-type calcium channels. To investigate the role of L-type calcium channels in the response to activation of $\mathrm{GABA}_{\mathrm{A}}$ receptors, we applied profiles of simulated $\mathrm{GABA}_{\mathrm{A}}$ conductances to $\mathrm{GnRH}$ somata using dynamic current clamping (see Materials and Methods) in conditions in which L-type calcium channels were active or pharmacologically blocked.

Figure 2 shows representative firing during dynamic clamping for two different profiles of simulated GABAergic excitation in two responder GnRH neurons before and after bath application of the L-type calcium channel blocker nimodipine (10 $\mu \mathrm{M} ; n=7$ responders). The same profile of simulated GABAergic conductances was used in control and nimodipine-treated conditions in individual GnRH neurons to allow for a direct comparison. Different profiles of GABAergic excitation (but with the same overall input frequencies) were applied between GnRH neurons to control for any effects of a particular conductance profile. Blocking L-type calcium channels reduced frequencies of firing by $75 \%$ in responsive GnRH neurons. Figure $2 B$ shows spike-triggered averaging on the simulated GABAergic conductance in the same responder GnRH neuron before and after bath application of nimodipine. All action potentials were aligned to time 0 , and the changes in conductance associated with action potentials are

\section{A With CNQX (10 uM) in bath}

First $25 \mathrm{sec}$ of $10 \mathrm{~min}$ recording



Last $25 \mathrm{sec}$ of $10 \mathrm{~min}$ recording
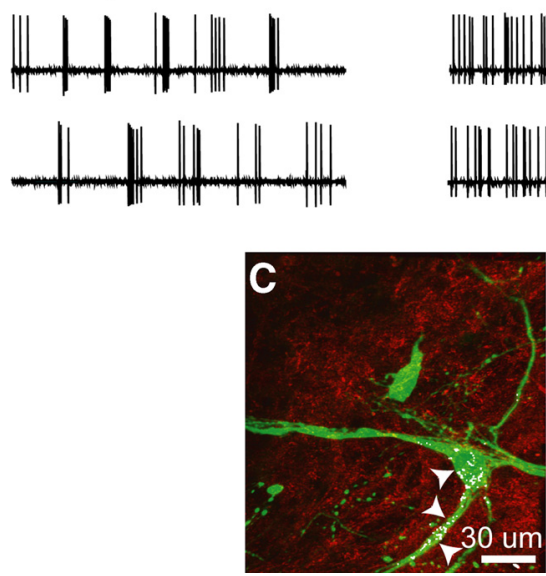

Last $25 \mathrm{sec}$ of $10 \mathrm{~min}$ recording
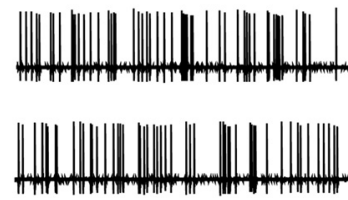

$20 \mathrm{mVI}$

$1 \mathrm{sec}$

Figure 3. Cell-attached recordings from GnRH neurons indicate that L-type calcium channels contribute to high-frequency discharges. In the presence of functional L-type calcium channels, $\mathrm{GnRH}$ neurons in adult male mice exhibit short bursts of action potentials $(\boldsymbol{A})$. Following addition of nimodipine $(10 \mu \mathrm{m})$ to the bath perfusate, the pattern of discharge shifts to an irregular pattern with a reduced frequency of action potentials $(\boldsymbol{B})$. Recorded neurons express L-type calcium channels in somata and proximal dendrites (C).

plotted (see Materials and Methods). When L-type calcium channels were blocked (gray line), higher conductance magnitudes were required to evoke action potentials in response to excitatory GABA relative to the condition in which L-type channels were active (black trace). Our electrophysiological findings with dynamic clamping are consistent with the hypothesis that activation of L-type calcium channels contributes to excitation mediated by GABA in GnRH neurons.

To determine the impact of L-type calcium channels on endogenous activity in GnRH neurons, we performed cell-attached recordings (Fig. 3). In the absence of AMPA-mediated excitation, short bursts of action potentials occurred throughout the duration of the $10 \mathrm{~min}$ recording (Fig. 3A). Bath application of the L-type calcium channel antagonist nimodipine $(10 \mu \mathrm{M})$ shifted the firing pattern in $\mathrm{GnRH}$ neurons from one composed of short bursts to an irregular pattern of firing (Fig. 3B). The coefficients of variation of action potentials before and following nimodipine application were $2.70( \pm 0.10)$ and $1.8( \pm 0.11)$, respectively. Including nimodipine in the bath perfusate also significantly reduced the frequency of action potentials from $1.84( \pm 0.24)$ to $0.55( \pm 0.12) \mathrm{Hz}$. This was largely due to eliminating highfrequency bursts of action potentials. Following immunocytochemistry on recorded slices, recorded GnRH neurons $(n=7)$ were positive for L-type calcium channels in somata and proximal GnRH dendrites (at arrowheads in Fig. 3C).

Multiple $\mathrm{Ca}^{2+}$ channel subtypes play a role in regulating activity of GnRH neurons. For example, periodic oscillations in intracellular 
calcium rely on inositol-1,4,5-trisphosphate receptor activation and store-dependent release, as opposed to plasma membrane ligand- or voltage-gated calcium channels (Jasoni et al., 2007). Likewise, $\mathrm{N}$-type channels appear to be important in the migration of $\mathrm{GnRH}$ neurons in the early embryonic period (Toba et al., 2005). L-type channels are important in the activity of model GnRH neurons (i.e., GT1-7 cells) (LeBeau et al., 2000; Van Goor et al., 2000). Moreover using dispersed somata, Nunemaker et al. (2003) reported that, of the high-voltage-activated calcium currents, the L- and N-type each comprised $\sim 25 \%$ of calcium currents. In the present study, we have shown that GABA-mediated activity in GnRH neurons is greatly reduced by blocking currents mediated by plasma membrane voltage-gated L-type calcium channels. Furthermore, the concentration of L-type calcium channels in GnRH somata and proximal dendrites is consistent with earlier observations in hippocampal pyramidal neurons (Westenbroek et al., 1990). However, in the $300 \mu \mathrm{m}$ slices used for electrophysiological recordings, the dendrites of $\mathrm{GnRH}$ neurons often extended into deeper regions of the slice in which penetration of antibodies used for immunocytochemistry would be questionable. To determine whether gradients in L-type calcium channels are present in GnRH dendrites, we applied immunocytochemistry in hypothalamic sections (50 $\mu \mathrm{m}$ not used for recordings).

Figure 4 establishes a biphasic gradient in L-type calcium channels in GnRH somata and dendrites. We term the gradient in calcium conductances "biphasic" because calcium currents in proximal dendrites (i.e., $0-26 \mu \mathrm{m})$ and distal dendrites $(\sim 130$ $\mu \mathrm{m}$ dendrite length) were comparable but were separated by intervening midlengths of dendrite $(\sim 27-130 \mu \mathrm{m})$ with reduced L-type calcium channels.

Approximately one-half of the GnRH neurons (65.2\%) were positive for L-type calcium channels in either somata and proximal dendrites or both (Fig. $4 A-C$ ). Previously, it has been reported that $\mathrm{GnRH}$ neurons exhibit a marked variation in activity of voltage-gated L-type calcium channels including variability in current densities and peak conductances (Spergel, 2007). Since these earlier studies relied on current-voltage relationships in response to somatic current injection, the inferences were largely limited to calcium channels in GnRH somata and proximal dendrites. As noted by Spergel (2007) and above with respect to dynamic current clamping, studies of dendritic calcium conductances are complicated due to both the lack of ability to control voltage in dendritic process and the attenuation of somatically applied voltage signals due to passive decay of applied current, the so-called space-clamp error. Our anatomical findings support the earlier electrophysiological findings in that L-type calcium conductances identified in GnRH somata by immunocytochemistry are highly variable. In the present study, not all GnRH somata or proximal dendrites expressed L-type calcium channels. Therefore, the variations in current densities and peak currents noted by Spergel (2007) most likely reflect true differences in calcium current expression in GnRH neurons.

Data in the present study extend these earlier findings regarding calcium conductances in GnRH neurons by defining a distinctive gradient in L-type calcium conductances along the length of GnRH dendrites. The dendritic presence and distribution of conductances is often characteristic within a population of neurons. Expression of individual conductances varies from uniform along the dendrite, or a gradient that increases or decreases along the dendrite (for discussion of dendritic distribution of conductances, see Migliore and Shepherd, 2002). Some GnRH neurons were devoid of somatic staining, but L-type calcium channels were apparent in proximal and distal dendrites (Fig. 4C-E).


Figure 4. Dendritic gradients in the distribution of L-type calcium channels in GnRH neurons. Approximately one-half of $\mathrm{GnRH}$ neurons express L-type calcium channels in somata and proximal dendrites (at arrowheads in $A$; the asterisk indicates a GnRH somata without immunoreactivity for L-type calcium channels). A GnRH neuron with only modest staining for L-type calcium channels in somata (B). A GnRH neuron with L-type calcium channels in the proximal dendrite (at arrowheads in O. Representative GnRH neurons with L-type calcium channels in the distal dendrites (at arrowheads in $\boldsymbol{D}$ and $\boldsymbol{E}$ ). $\boldsymbol{F}$, Distribution of L-type calcium channels in $\mathrm{GnRH}$ somata and dendrites.

When L-type calcium channels were quantified along the length of GnRH dendrites, somatic expression was significantly higher than dendritic expression. However, the magnitude of expression in the most proximal portions of the dendrite $(0-26 \mu \mathrm{m})$ was comparable with expression in the most distal portions of $\mathrm{GnRH}$ dendrites ( $>130 \mu \mathrm{m}$; Fig. $4 F)$. Thus, GABAergic inputs could interact with L-type calcium channels in GnRH somata as well as proximal and portions of very distal dendrites.

As noted above, applying simulated inputs to somata via dynamic current clamping may not adequately reflect interactions when inputs are distributed along the dendrite. In the present case, inputs applied with dynamic current clamping would be largely limited to activation of L-type calcium channels on GnRH somata and perhaps proximal dendrites. Dynamic clamping (which requires the whole-cell recording configuration) of $\mathrm{GnRH}$ distal dendrites is not tractable due to the small diameters. Thus, we used uncaging of GABA along the GnRH dendrite to examine GABAergic input and their interaction with L-type calcium conductances.

Figure 5 shows responses to uncaging GABA on a GnRH soma (Fig. 5A) and at 100 and $200 \mu \mathrm{m}$ of dendrite length (Fig. 5B, C, 
respectively) in the same neuron. GABA was uncaged at least five times in each location. We considered the soma and most proximal portions of the dendrite (i.e., $0-26 \mu \mathrm{m}$ of dendrite length) as one compartment, which we termed somatic/ proximal dendritic region. We termed the dendritic lengths from 27 to $129 \mu \mathrm{m}$ the middendritic region and lengths $>130$ $\mu \mathrm{m}$ to be distal dendritic regions. All responses to GABA uncaging in all tested neurons $(n=16)$ were repeatable (Fig. $5 A-C)$ and eliminated with bath application of picrotoxin $(40 \mu \mathrm{M})$. The response to activation of $\mathrm{GABA}_{\mathrm{A}}$ receptors via uncaging GABA as measured by PSC amplitude was significantly reduced in midand distal dendritic locations relative to somatic/proximal dendritic uncaging (Fig. 5D). Because these recordings were performed in voltage clamp, it was impossible to distinguish whether the results reflected a decreasing gradient in $\mathrm{GABA}_{\mathrm{A}}$ receptors along the dendrite as reported in earlier studies (Cottrell et al., 2006) or passive decay of the induced PSC over the dendritic length to the point of detection at the somatic recording electrode.

To determine whether activation of $\mathrm{GABA}_{\mathrm{A}}$ receptors and presumably GABAergic synapses along GnRH dendrites could generate action potentials, we shifted our uncaging experiments to the current-clamp recording mode. Uncaging of GABA on GnRH somata/proximal dendritic regions resulted in repetitive action potentials, superimposed on large postsynaptic potentials (PSPs) (Fig. 6A, top traces). The action potential response to uncaged GABA decreased at 100 $\mu \mathrm{m}$ of dendrite length (Fig. $6 B$, top traces). At $200 \mu \mathrm{m}$ dendrite length, action potentials were not evoked by the same uncaged GABA stimulus (Fig. $6 C$, top traces), consistent with a reduction in $\mathrm{GABA}_{\mathrm{A}}$ receptors and a decreasing outward gradient in GABAergic innervations along the dendrite (Cottrell et al., 2006). Thus, despite the high axial resistance of distal GnRH dendrites, activation of any existing $\mathrm{GABA}_{\mathrm{A}}$ receptors was not sufficient to generate dendritic action potentials. Accordingly, the frequency of action potentials in response to uncaging GABA decreased significantly along the dendrite length (Fig. 6D).

We previously demonstrated a biphasic anatomical gradient in L-type calcium channels in GnRH dendrites (Fig. $4 F$ ) whereby proximal L-type calcium channels at $0-26 \mu \mathrm{m}$ of dendrite length were comparable with those at $>130 \mu \mathrm{m}$ of dendrite length. The expression of active ionic conductances in the dendritic tree can, depending on location, "normalize" the capacitance-induced distortion of synaptic signals (Cook and Johnston, 1999), lead to plateau potential generation, oscillations, and bistability resulting in repetitive action potential generation (Dickson et al., 2000), and boost the effectiveness of distal synaptic inputs (Schiller and Schiller, 2001). Such processes can fundamentally change the integrative function of neurons. Therefore, we repeated uncaging of GABA at GnRH somata and along the length of the $\mathrm{GnRH}$ dendrite in the presence of nimodipine $(10 \mu \mathrm{M})$.

Figure 6, bottom traces, shows the response to uncaging GABA in the same GnRH neurons as the initial GABA uncaging shown in the top traces. Activation of somatic/proximal dendritic $\mathrm{GABA}_{\mathrm{A}}$ receptors resulted in robust action potential discharges superimposed on large PSPs. Bath application of nimodipine eliminated somatic action potentials and reduced the magnitude of PSPs (Fig. 6A, bottom traces). Likewise, action potentials generated at $100 \mu \mathrm{m}$ of dendrite length in response to uncaging of GABA were eliminated in the presence of nimodipine with a corresponding reduction in the PSP amplitude (Fig. $6 \mathrm{~B}$, bottom traces). Blocking L-type calcium channels had no effect on action potential generation at $200 \mu \mathrm{m}$ of dendrite length but continued to reduce the PSP amplitude. Area under the curve of averaged PSPs generated in response to uncaging GABA was significantly reduced at each successively more distal location of uncaging. The frequency of action potentials was significantly reduced in both GnRH somata and proximal dendrites by bath application of nimodipine (Fig. 6D). These findings are consistent with a decreasing gradient in $\mathrm{GABA}_{\mathrm{A}}$ receptors and a decreasing impact of activating L-type calcium channels along the dendrite length. Moreover, based on the magnitude and shape of the PSP response, they suggest that L-type calcium channels mediate a substantial component of both suprathreshold and subthreshold responses to GABA. Thus, L-type calcium channels may amplify the impact of even modest changes in GABAergic PSCs.

Glutamate and GABA are dominant fast neurotransmitters in the hypothalamus. Therefore, we determined whether the actions of glutamate also engage L-type calcium channels. We performed dynamic current clamping and uncaging of glutamate in ACSF and in ACSF with nimodipine $(10 \mu \mathrm{M})$ in the bath perfusate. Application of simulated AMPA-type inputs to GnRH neurons via dynamic current clamping (Fig. $7 \mathrm{~A}$, black traces) resulted in 


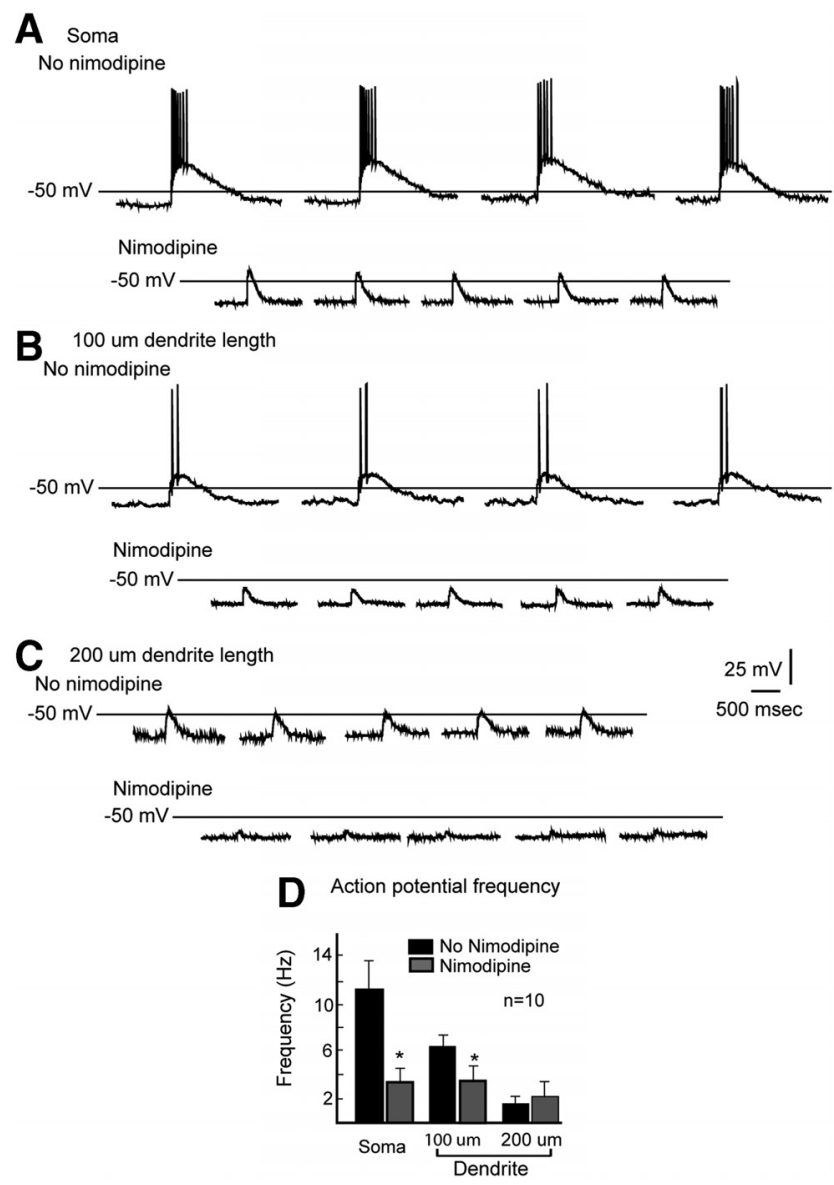

Figure 6. Blocking L-type calcium channels reduces the response to uncaging GABA. Each trace shows a repeated response to GABA uncaging (top traces) and GABA uncaging in the absence of functional L-type calcium channels (bottom traces). Robust action potentials occur when GABA is uncaged on GnRH somata ( $\boldsymbol{A}$; top trace). Action potentials are reduced when L-type calcium channels are blocked ( $\boldsymbol{A}$; bottom trace). Action potentials are elicited by uncaging GABA at $100 \mu \mathrm{m}$ of dendrite length ( $\boldsymbol{B}$; top traces) and reduced when L-type calcium channels are blocked ( $\boldsymbol{B}$; bottom traces). Action potentials are not generated when GABA is uncaged on $\mathrm{GnRH}$ dendrites at $100 \mu \mathrm{m}$ of dendrite length ( $\boldsymbol{C}$; top trace). Significantly lower action potential frequencies occur in response to uncaging GABA on GnRH dendrites compared with $\mathrm{GnRH}$ somata ( $\boldsymbol{D}$; black bars). Blocking L-type calcium channels reduces response to uncaging GABA on both $\mathrm{GnRH}$ somata and dendrites ( $\boldsymbol{D}$; gray bars). The asterisks indicate significance at $p \leq 0.05$ within groups between neuronal regions (black bars) and within regions between treatments (gray bars). Error bars indicate SEM.

trains of action potentials. The addition of nimodipine $(10 \mu \mathrm{M})$ to the bath perfusate did not alter the response of $\mathrm{GnRH}$ neurons to simulated AMPA-type inputs (Fig. 7A, gray traces).

As previously noted, simulated conductances are applied at the somata, and, as such, the passive decay limits their influence to somata and the most proximal dendrites. The finding that nimodipine significantly reduced action potentials driven by simulated GABA by $75 \%$ (Fig. 2) but did not alter the response of GnRH neurons to simulated AMPA indicates that, in approximately one-half of GnRH neurons, GABAergic input activates L-type calcium channels in somata/proximal dendrites to generate action potentials simulated AMPA inputs do not.

We then determined whether glutamatergic input on $\mathrm{GnRH}$ dendrites activates L-type calcium channels (Fig. $7 \mathrm{~B}, \mathrm{C}$ ). Adding nimodipine $(10 \mu \mathrm{M})$ to the bath perfusate completely eliminated the response to uncaging of glutamate on $\mathrm{GnRH}$ somata and

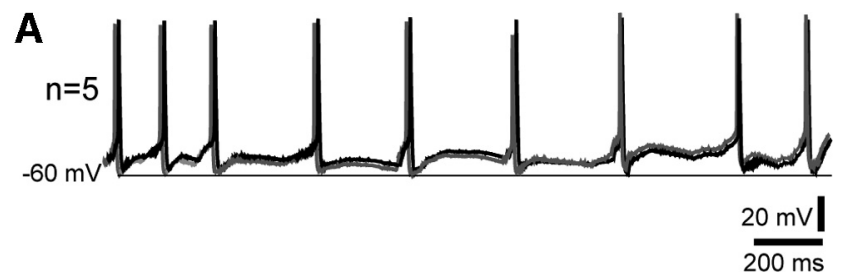

B Completely Blocked

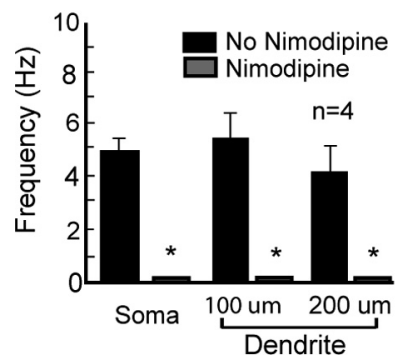

C Partially Blocked



Figure 7. The response of GnRH neurons to simulated AMPA-type inputs ( $\boldsymbol{A}$, black traces) is not altered by addition of nimodipine ( $10 \mu \mathrm{M})$ to the bath perfusate $(\boldsymbol{A}$, gray traces). In contrast, the response to uncaging of glutamate on $\mathrm{GnRH}$ somata and along $\mathrm{GnRH}$ dendrites $(\boldsymbol{B}, \boldsymbol{C}$, black bars; $n=8)$ was completely eliminated in the presence of nimodipine $(10 \mu \mathrm{m})$ in the bath perfusate ( $\boldsymbol{B}$, gray bars; $n=4)$ but was only reduced in a second population of $\mathrm{GnRH}$ neurons ( $\boldsymbol{C}$, gray bars; $n=4)$. The asterisks indicate significance at $p \leq 0.05$ within groups at the same location. Error bars indicate SEM.
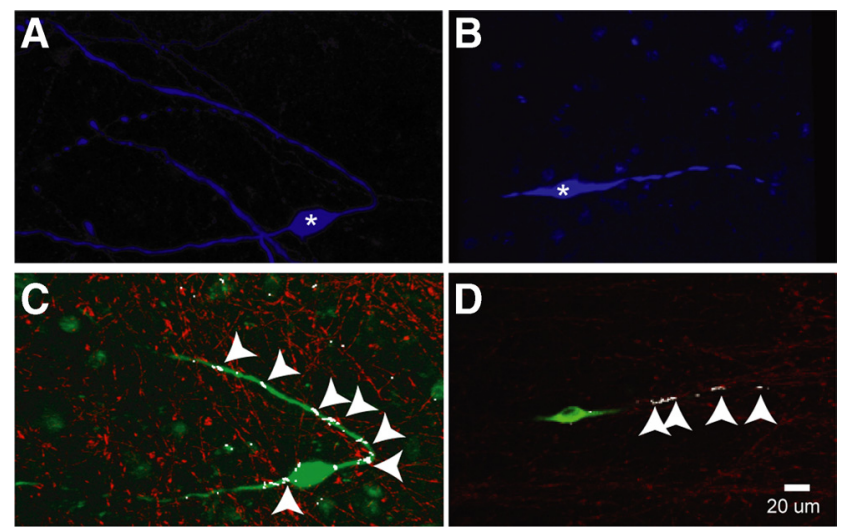

Figure 8. GnRH neurons relocated after GABA uncaging experiments and analyzed for L-type calcium channel immunoreactivity. Biocytin-filled $\mathrm{GnRH}$ neurons $(\boldsymbol{A}, \boldsymbol{B})$. Distribution of $\mathrm{L}$-type calcium channels in $\mathrm{GnRH}$ neurons used during GABA uncaging experiments $(\boldsymbol{C}, \boldsymbol{D})$.

along GnRH dendrites in one population of GnRH neurons (Fig. $7 B ; n=4)$. However, the response was only reduced in a second population of GnRH neurons (Fig. $7 C ; n=4$ ). Thus, the uncaging of glutamate reveals two populations of $\mathrm{GnRH}$ neurons. In one population, glutamatergic inputs seem to activate L-type calcium channels, while in the second population, the effect of glutamate is less dependent on L-type calcium channels.

Figure 8 shows GnRH neurons filled during GABA uncaging experiments, which were relocated based on avidin-Casade blue (Fig. 8A, $B$ ). Immunocytochemistry was performed slices containing recorded neurons to identify L-type calcium channels (Fig. 8C,D). Higher densities of L-type calcium channels were found in proximal dendritic regions than in more distal regions, a finding that was consistent with the loss of action potentials in response to uncaging GABA in the absence of functional L-type calcium channels. 


\section{Discussion}

Dendrites of GnRH neurons were often viewed as passive linear elements whose major role was collecting information arising from activation of synaptic inputs and conveying the resulting PSPs to somata (Roberts et al., 2006). The finding that GnRH dendrites express voltage-gated sodium channels and are capable of action potential initiation (Roberts et al., 2008a), interact with other GnRH dendrites in bundles and share synapses (Campbell et al., 2009), and reside outside the blood-brain barrier (Herde et al., 2011) has stimulated interest in the function of GnRH dendrites and their contribution to $\mathrm{GnRH}$ release.

\section{Response to fast neurotransmitters reveals subpopulations of GnRH neurons}

The present study demonstrates subpopulations of GnRH neurons based on their response to either application of simulated conductances on somata/proximal dendrites or uncaging of GABA and glutamate along the length of their dendrites. Subpopulations of $\mathrm{GnRH}$ neurons also emerge based on response to GABAergic and glutamatergic input from the anteroventral periventricular nucleus (AVPV) (Liu et al., 2011). In male mice, $\sim 70 \%$ of GnRH neurons responded to GABA release from AVPV neurons. We also find $\sim 70 \%$ of $\mathrm{GnRH}$ neurons respond to simulated GABA input. This response is dependent on L-type calcium channels. Thus, GnRH neurons that exhibit GABAergic PSCs in response to AVPV activation could differ in densities of somatic/proximal L-type calcium channels.

Uncaging glutamate also suggested subpopulations of $\mathrm{GnRH}$ neurons. Specifically, glutamatergic stimulation strongly activated L-type calcium channels in $\sim 50 \%$ of GnRH neurons. Thus, AMPA-mediated inputs likely share the calcium channel amplification mechanism with GABAergic inputs.

The response to uncaging glutamate differed between $\mathrm{GnRH}$ dendrites but was consistent within the same GnRH dendrite. However, the uncaging GABA response differed within $\mathrm{GnRH}$ dendrites. This observation, in conjunction with the prominent GABAergic input to GnRH neurons (Sim et al., 2000), suggested the presence of a potential microdomain.

\section{Earlier microdomains in $\mathrm{GnRH}$ dendrites}

Afterdepolarization potentials (ADPs) underlie repetitive firing in magnocellular neuroendocrine neurons (Stern and Armstrong, 1996). Studies in GnRH neurons (Chu and Moenter, 2006) and in isolated GnRH somata (Kuehl-Kovarik et al., 2005) suggested that ADPs would contribute to repetitive firing in GnRH neurons. Our studies using multicompartment modeling and electrophysiological recordings indicated length of $\mathrm{GnRH}$ dendrites directly determined ADP amplitude and whether repetitive firing occurred following ADPs. The impact of dendrite length was independent of dendritic voltage-gated sodium channels (Roberts et al., 2009). Thus, this anatomical "microdomain" in which large ADPs were generated and led to repetitive action potentials reflects purely passive membrane properties in regions of $100 \mu \mathrm{m}$ or less of dendritic length.

After determining that GnRH dendrites expressed voltagegated sodium channels, modeling experiments suggested the presence of functional microdomains in which voltage-gated sodium channels interacted with glutamatergic synapses. Activation of simulated synapses in defined dendritic regions resulted in preferential generation of action potentials from dendrites (Roberts et al., 2008a). Although no conductance gradient in voltagegated sodium channels was identified in GnRH dendrites in the initial study, the possibility that such gradients exist cannot be excluded. However, anatomical gradients in glutamatergic and GABAergic inputs have been identified along dendrites (Cottrell et al., 2006). Oviedo and Reyes (2002) used living neurons to define differences in somatic and dendritic responses to excitation. In single pyramidal neurons, it appears inputs are preferentially "weighted" based on their location along the somatodendritic axis in single neurons (Oviedo and Reyes, 2005). Thus, the interplay between gradients in synaptic phenotypes, densities of innervation, and ionic conductances along GnRH dendrites suggested a functional microdomain in which generation of dendritic action potentials occurred in preference to somatic action potentials.

\section{A GABAergic/L-type calcium channel functional microdomain within GnRH dendrites}

In the present study, we define a functional microdomain in $\mathrm{GnRH}$ dendrites composed of two gradients. This first is a biphasic dendritic gradient in L-type calcium channels. The second gradient is decreasing GABAergic influence along the dendrite. The dynamic-clamping data in the present study along with two earlier studies (Spergel et al., 1995; Constantin et al., 2010) indicated that interaction between GABAergic inputs and L-type calcium conductances was probable in $\mathrm{GnRH}$ neurons. Constantin et al. (2010) demonstrated that the initial increase in intracellular calcium levels in response to activation of endogenous $\mathrm{GABA}_{\mathrm{A}}$ receptors reflected opening of L-type calcium channels. Likewise, activation of $\mathrm{GABA}_{\mathrm{A}}$ receptors on GT1-7 cells resulted in increases in intracellular calcium levels (Spergel et al., 1995). In the present study, we used dynamic current clamping to tightly control patterns and magnitudes of simulated $\mathrm{GABA}_{\mathrm{A}}$ input. In doing so, we find variable calcium channel expression lead to a divergence in responses from $\mathrm{GnRH}$ neurons to simulated GABAergic inputs applied using dynamic current clamping. Therefore, the additional findings of variable expression of L-type calcium channels along dendrites raised the potential differential processing of GABAergic signals in GnRH neurons.

Data from the present study indicate the variation in calcium conductances would render regions of GnRH neurons with more L-type calcium channels responsive to GABAergic inputs. Thus, the finding of a biphasic gradient in L-type calcium conductances along GnRH dendrites is particularly interesting in light of the earlier identification of a gradient in GABAergic input to $\mathrm{GnRH}$ dendrites using immunocytochemistry (Cottrell et al., 2006). In dendritic regions with robust presence of L-type calcium channels and GABAergic inputs, action potentials would occur with nearly the same efficacy as direct inputs to GnRH somata. The decreasing gradient in GABAergic inputs as the dendrite extends would suggest in specific regions of GnRH neurons, L-type calcium channels would not be activated, due to the absence of GABAergic inputs. Conversely, GABAergic signaling would be weaker in regions lacking the L-type channels used to amplify GABAergic PSPs to action potential threshold. Therefore, signals mediated by GABAergic synaptic input could either be amplified by the presence of L-type calcium channels or attenuated by their absence.

Based on photoactivation of caged-GABA, it seems that the areas that would be most strongly impacted by GABAergic synaptic activation would be GnRH somata and proximal dendrites in which L-type calcium channels are expressed. In these regions, action potentials would be generated by activation of L-type calcium channels by currents from $\mathrm{GABA}_{\mathrm{A}}$ receptor, much like the outcome in dynamic clamping of GnRH somata/proximal dendrites. In middendritic regions, GABAergic signaling would de- 
pend on the amplitude/frequency of GABAergic input and density of L-type channels. In the absence of L-type calcium channel "amplification," GABAergic EPSPs would either be passively attenuated along the dendrite length or, if sustained over passive decay, these GABAergic signals would activate L-type channels in the most proximal or more distal regions of dendrite (where L-type calcium channels are more abundant) or in $\mathrm{GnRH}$ somata. This would create a middendritic gate through which only relatively high-amplitude, low-frequency GABAergic signaling to dendrites would elicit action potentials in dendrites. Indeed, high-frequency, high-amplitude GABAergic inputs on regions having low expression of L-type calcium channels would create an electrical shunt of other synaptic signals by persistent subthreshold depolarization of dendritic membrane similar to the results of dynamic clamping in GnRH somata and proximal dendrites. In distal GnRH dendrites, one would be tempted to speculate that the return to higher levels of L-type calcium channel expression comparable with proximal dendrites, coupled with the higher resistance of the distal dendritic compartment (relative to the proximal compartment), would offset the decrease in GABAergic innervation, with the high resistance distal compartment functioning as an anatomical "amplifier" of currents. However, this was not the case. Instead, the decreasing gradient of GABAergic innervation resulted in weak responses to GABA uncaging and distal dendrites were unresponsive in terms of action potential generation. These dendritic segments may compose a completely different functional domain that depends on a different form of GABA-synaptic input. This underscores the complexity of the role that GABAergic inputs play in $\mathrm{GnRH}$ neurons.

Given the above considerations, it seems the GABAergic/Ltype calcium channel microdomain in $\mathrm{GnRH}$ dendrites is one in which proximal GABAergic signals are amplified through activation of L-type calcium channels and middendritic GABAergic signals are filtered. This middendritic zone may function as a coincidence detector and thus linearly sum incoming GABAergic signals or it could integrate over longer time frames, a divergence that has been observed in dendrites of other neurons (Branco and Häusser, 2011). Since GABAergic PSCs have relatively long time courses, it seems reasonable to speculate that it would serve in the latter regard.

\section{Implication of functional microdomains for physiological function of GnRH neurons}

GnRH dendrites present an integration and computational challenge. On one hand, the extensive dendritic arbors of other neurons are absent in GnRH neurons (Campbell et al., 2005; Roberts et al., 2006). On the other hand, GnRH neurons integrate and process the multitude of regulatory signals controlling pulsatile GnRH release (Herbison, 2006). Without highly branched dendrites, GnRH neurons lack the anatomical substrate of other neurons in which a single dendritic branch serves as a unit of integration (Branco and Häusser, 2010). The present study suggests a segment of the single nonbranching GnRH dendrite creates a functional microdomain and serves as a unit of integration.

\section{References}

Branco T, Häusser M (2010) The single dendritic branch as a fundamental functional unit in the nervous system. Curr Opin Neurobiol 20:494-502.

Branco T, Häusser M (2011) Synaptic integration gradients in single cortical pyramidal cell dendrites. Neuron 69:885-892.

Campbell RE, Han SK, Herbison AE (2005) Biocytin filling of adult gonadotropin-releasing hormone neurons in situ reveals extensive, spiny, dendritic processes. Endocrinology 146:1163-1169.
Campbell RE, Gaidamaka G, Han SK, Herbison AE (2009) Dendrodendritic bundling and shared synapses between gonadotropin-releasing hormone neurons. Proc Natl Acad Sci U S A 106:10835-10840.

Chu Z, Moenter SM (2006) Physiologic regulation of a tetrodotoxinsensitive sodium influx that mediates a slow afterdepolarization potential in gonadotropin-releasing hormone neurons: possible implications for the central regulation of fertility. J Neurosci 26:11961-11973.

Constantin S, Jasoni CL, Wadas B, Herbison AE (2010) Gammaaminobutyric acid and glutamate differentially regulate intracellular calcium concentrations in mouse gonadotropin-releasing hormone neurons. Endocrinology 151:262-270.

Cook EP, Johnston D (1999) Voltage-dependent properties of dendrites that eliminate location-dependent variability of synaptic input. J Neurophysiol 81:535-543.

Cottrell EC, Campbell RE, Han SK, Herbison AE (2006) Postnatal remodeling of dendritic structure and spine density in gonadotropin-releasing hormone neurons. Endocrinology 147:3652-3661.

DeFazio RA, Heger S, Ojeda SR, Moenter SM (2002) Activation of A-type gamma-aminobutyric acid receptors excites gonadotropin-releasing hormone neurons. Mol Endocrinol 16:2872-2891.

Dickson CT, Magistretti J, Shalinsky MH, Fransén E, Hasselmo ME, Alonso A (2000) Properties and role of $I_{\mathrm{h}}$ in the pacing of subthreshold oscillations in entorhinal cortex layer II neurons. J Neurophysiol 83:2562-2579.

Gulledge AT, Stuart GJ (2003) Excitatory actions of GABA in the cortex. Neuron 37:299-309.

Hemond PJ, Suter KJ (2010) Dual somatic recordings from gonadotropinreleasing hormone $(\mathrm{GnRH})$ neurons identified by green fluorescent protein (GFP) in hypothalamic slices. J Vis Exp 2010:pii:1678.

Herbison AE (2006) Physiology of the GnRH neuronal network. In: Knobil and Neill's physiology of reproduction, Vol 1, Chap 28 (Neill JD, ed), pp 1415-1482. San Diego: Academic.

Herde MK, Geist K, Campbell RE, Herbison AE (2011) Gonadotropinreleasing hormone neurons extend complex highly branched dendritic trees outside the blood-brain barrier. Endocrinology 152:3832-3841.

Jasoni CL, Todman MG, Strumia MM, Herbison AE (2007) Cell typespecific expression of a genetically encoded calcium indicator reveals intrinsic calcium oscillations in adult gonadotropin-releasing hormone neurons. J Neurosci 27:860-867.

Kuehl-Kovarik MC, Partin KM, Handa RJ, Dudek FE (2005) Spikedependent depolarizing afterpotentials contribute to endogenous bursting in gonadotropin releasing hormone neurons. Neuroscience 134:295-300.

LeBeau AP, Van Goor F, Stojilkovic SS, Sherman A (2000) Modeling of membrane excitability in gonadotropin-releasing hormone-secreting hypothalamic neurons regulated by $\mathrm{Ca}^{2+}$-mobilizing and adenylyl cyclasecoupled receptors. J Neurosci 20:9290-9297.

Lee HH, Deeb TZ, Walker JA, Davies PA, Moss SJ (2011) NMDA receptor activity downregulates $\mathrm{KCC} 2$ resulting in depolarizing $\mathrm{GABA}_{\mathrm{A}}$ receptormediated currents. Nat Neurosci 14:736-743.

Leupen SM, Tobet SA, Crowley WF Jr, Kaila K (2003) Heterogeneous expression of the potassium-chloride cotransporter KCC2 in gonadotropinreleasing hormone neurons of the adult mouse. Endocrinology 144: 3031-3036.

Lipscombe D, Helton TD, Xu W (2004) L-type calcium channels: the low down. J Neurophysiol 92:2633-2641.

Liu X, Porteous R, d'Anglemont de Tassigny X, Colledge WH, Millar R, Petersen SL, Herbison AE (2011) Frequency-dependent recruitment of fast amino acid and slow neuropeptide neurotransmitter release controls gonadotropin-releasing hormone neuron excitability. J Neurosci 31:2421-2430.

Migliore M, Shepherd GM (2002) Emerging rules for the distributions of active dendritic conductances. Nat Rev Neurosci 3:362-370.

Moenter SM, DeFazio RA (2005) Endogenous gamma-aminobutyric acid can excite gonadotropin-releasing hormone neurons. Endocrinology 146:5374-5379.

Nunemaker CS, DeFazio RA, Moenter SM (2003) Calcium current subtypes in GnRH neurons. Biol Reprod 69:1914-1922.

Oviedo H, Reyes AD (2002) Boosting of neuronal firing evoked with asynchronous and synchronous inputs to the dendrite. Nat Neurosci $5: 261-266$.

Oviedo H, Reyes AD (2005) Variation of input-output properties along the somatodendritic axis of pyramidal neurons. J Neurosci 25:4985-4995. 
Roberts CB, Best JA, Suter KJ (2006) Dendritic processing of excitatory synaptic input in hypothalamic gonadotropin releasing-hormone $(\mathrm{GnRH})$ neurons. Endocrinology 147:1545-1555.

Roberts CB, Campbell RE, Herbison AE, Suter KJ (2008a) Dendritic action potential initiation in hypothalamic gonadotropin-releasing hormone (GnRH) neurons. Endocrinology 149:3355-3360.

Roberts CB, Hemond P, Suter KJ (2008b) Synaptic integration in hypothalamic gonadotropin releasing hormone neurons. Neuroscience 154:1337-1351.

Roberts CB, O'Boyle MP, Suter KJ (2009) Dendrites determine the contribution of after depolarization potentials (ADPs) to generation of repetitive action potentials in hypothalamic gonadotropin releasing-hormone (GnRH) neurons. J Comput Neurosci 26:39-53.

Schiller J, Schiller Y (2001) NMDA receptor-mediated dendritic spikes and coincident signal amplification. Curr Opin Neurobiol 11:343-348.

Sharp AA, O'Neil MB, Abbott LF, Marder E (1993) Dynamic clamp: computer-generated conductances in real neurons. J Neurophysiol 69:992-995.

Sim JA, Skynner MJ, Pape JR, Herbison AE (2000) Late postnatal reorganization of $\mathrm{GABA}_{\mathrm{A}}$ receptor signalling in native $\mathrm{GnRH}$ neurons. Eur J Neurosci 12:3497-3504

Sim JA, Skynner MJ, Herbison AE (2001) Heterogeneity in the basic membrane properties of postnatal gonadotropin-releasing hormone neurons in the mouse. J Neurosci 21:1067-1075.

Spergel DJ (2007) Calcium and small-conductance calcium-activated potassium channels in gonadotropin-releasing hormone neurons before, during, and after puberty. Endocrinology 148:2383-2390.

Spergel DJ, Krsmanovic LZ, Stojilkovic SS, Catt KJ (1995) L-type Ca ${ }^{2+}$ channels mediate joint modulation by gamma-amino-butyric acid and glutamate of $\left[\mathrm{Ca}^{2+}\right]_{\mathrm{i}}$ and neuropeptide secretion in immortalized gonadodropin-releasing hormone neurons. Neuroendocrinology 61:499-508.

Spergel DJ, Krüth U, Hanley DF, Sprengel R, Seeburg PH (1999) GABAand glutamate-activated channels in green fluorescent protein-tagged gonadotropin-releasing hormone neurons in transgenic mice. J Neurosci 19:2037-2050.

Stern JE, Armstrong WE (1996) Changes in the electrical properties of supraoptic nucleus oxytocin and vasopressin neurons during lactation. J Neurosci 16:4861-4871.

Sullivan SD, Moenter SM (2004) GABAergic neurons integrate and rapidly transmit permissive and inhibitory metabolic cues to $\mathrm{GnRH}$ neurons. Endocrinology 145:1194-1202.

Sullivan SD, DeFazio RA, Moenter SM (2003) Metabolic regulation of fertility through presynaptic and postsynaptic signaling to gonadotropinreleasing hormone neurons. J Neurosci 23:8578-8585.

Suter KJ (2004) Control of firing by small AMPA-type inputs in hypothalamic gonadotropin-releasing hormone $(\mathrm{GnRH})$ neurons. Neuroscience 128:443-450.

Toba Y, Pakiam JG, Wray S (2005) Voltage-gated calcium channels in developing GnRH-1 neuronal system in the mouse. Eur J Neurosci 22:79-92.

Van Goor F, LeBeau AP, Krsmanovic LZ, Sherman A, Catt KJ, Stojilkovic SS (2000) Amplitude-dependent spike-broadening and enhanced $\mathrm{Ca}^{2+}$ signaling in GnRH-secreting neurons. Biophys J 79:1310-1323.

Westenbroek RE, Ahlijanian MK, Catterall WA (1990) Clustering of L-type $\mathrm{Ca}^{2+}$ channels at the base of major dendrites in hippocampal pyramidal neurons. Nature 347:281-284. 